\title{
Commentaries
}

\section{GRP and Pavlov's dogs}

The cephalic phase of gastric acid secretion has been a topic of great interest to physiologists and physicians since its description by Pavlov 100 years ago. ${ }^{1}$ In classic "sham" feeding studies performed on dogs equipped with an oesophageal stoma and a gastric fistula, Pavlov demonstrated that food was a prompt and powerful stimulant of gastric secretion. This stimulation occurred despite the fact that the ingested food entered the dog's mouth and pharynx and exited through the stoma, never actually reaching the stomach. Pavlov went on to demonstrate that severing the vagus nerves just above the diaphragm abolished the gastric acid secretory response to sham feeding in dogs. His experiments demonstrated that sham feeding elicited a potent gastric acid secretory response via the vagus nerves.

Although experiments involving surgically created fistulas could not be conducted in humans, in the 1970s Knutson and Olbe developed a "modified" sham feeding technique to study the cephalic phase of gastric acid secretion in patients with duodenal ulcer disease. ${ }^{2-4}$ Patients chewed and expectorated appetising food without swallowing it, and a tube inserted into the stomach collected gastric fluid for acid analysis. Using modified sham feeding in healthy volunteers, Richardson et al demonstrated that the cephalic phase of gastric acid secretion accounted for half of the acid secreted during the first postprandial hour. ${ }^{5}$ The thought and taste of food were more important secretory stimulants than the sight or smell of a meal. ${ }^{6}$ Acetylcholine and histamine were demonstrated to be important mediators of the cephalic phase of gastric acid secretion in humans because injection of either the muscarinic antagonist atropine or the histamine $\mathrm{H}_{2}$ receptor antagonist cimetidine markedly attenuated the acid secretory response to modified sham feeding. ${ }^{78}$ Much as Pavlov had demonstrated in dogs, clinical investigators found that the cephalic phase of gastric acid secretion in humans could also be abolished by surgical vagotomy, even by a proximal selective vagotomy which preserved the vagal innervation of the gastric antrum and pylorus. ${ }^{29}$

The antral hormone gastrin is released into the blood during the cephalic phase of gastric acid secretion in humans. ${ }^{4-7910}$ Although the amount of gastrin released during modified sham feeding is small in comparison with the amount released during normal eating, the serum increase in gastrin probably contributes to a substantial proportion of the acid secreted during modified sham feeding. In contrast with acid secretion, cephalic-vagal release of gastrin cannot be blocked by large doses of atropine. ${ }^{7}$ In fact, atropine potentiates gastrin release during modified sham feeding, indicating that an inhibitory vagal-cholinergic pathway normally operates to limit gastrin release during the cephalic phase. In support of this mechanism, augmentation of gastrin release during modified sham feeding has been demonstrated after proximal selective vagotomy. ${ }^{9}$ The noncholinergic neurotransmitter that is responsible for release of gastrin from the antrum of the stomach during the cephalic phase in humans is not known but gastrin releasing peptide (GRP) has been a prime candidate.
GRP is the mammalian analogue of bombesin, a 14 amino acid peptide which was first isolated from the skin of two frogs, Bombina bombina and Bombina variegata variegata. ${ }^{11} 12$ Both bombesin and GRP are potent gastrin releasers and acid secretogogues when injected into humans. ${ }^{13-16}$ Soon after bombesin was discovered in frog skin, a similar gastrin releasing peptide was extracted from the non-antral portion of the pig stomach. ${ }^{17}{ }^{18}$ Using specific antibodies to bombesin/GRP, GRP was later demonstrated in the human stomach by immunostaining. ${ }^{19}$ Of interest, GRP neurones are actually denser in the fundic (oxyntic) mucosa, where acid secreting parietal cells are located, than in the antral (pyloric) mucosa, where gastrin cells (G cells) are located. ${ }^{19}$

Until recently, no specific GRP antagonist has been available to explore GRP as a potential physiological mediator of vagally mediated gastrin release or of acid secretion during the cephalic phase in humans. Now, a novel synthetic peptide that is a specific peripheral GRP receptor antagonist (GRP-RA) has been tested by Hildebrand $e t a l$, and their interesting results are reported in this issue of Gut (see page 23). ${ }^{20}$ Surprisingly, the GRP-RA had no effect on the amount of gastrin released in response to modified sham feeding or in response to normal eating. This suggests that the term "gastrin releasing peptide" may be a misnomer, at least with regard to the physiological action of this neuropeptide. Thus the identity of the non-cholinergic non-GRP stimulant of antral gastrin release during the cephalic phase of acid secretion remains to be determined; it is even possible that the "stimulant" is in fact removal of an endogenous gastrin inhibitor, such as antral somatostatin.

An equally important finding in the study by Hildebrand et al was that the same dose of GRP receptor antagonist that had no detectable effect on gastrin release (500 $\mu \mathrm{g} / \mathrm{kg} / \mathrm{h}$ ) abolished the gastric acid secretory response to modified sham feeding, and it also abolished acid secretion in response to intravenous GRP infusion. This striking observation implies a critical role for GRP neurones, presumably those located in the fundic (oxyntic) mucosa, in the regulation of gastric acid secretion during the cephalic phase. Activated by the thought, taste, smell, and sight of food, the vagus nerves may stimulate release of GRP from these intramural gastric neurones, which then might evoke acetylcholine release from postganglionic neurones, with acetylcholine binding muscarinic receptors located on parietal cells. This hypothetical cascade remains to be tested experimentally. It is conceivable that drugs that selectively inhibit GRP receptors in the stomach can be developed as acid antisecretory drugs, resulting in a "medical" vagotomy. We have learned a great deal about the cephalic phase of acid secretion since the pioneering studies in Pavlov's dogs, but clearly we still have a great deal more to learn. Neuronal GRP appears to be a critical piece of the puzzle.

M FELDMAN

Department of Veterans Affairs North Texas Health Care System and Department of Internal Medicine,

University of Texas Southwestern Medical Center,

Dallas, TX, USA

mark.feldman@med.va.gov 
1 Pavlov IP. The centrifugal (efferent) nerves to the gastric glands and of the pancreas. In: Thompson WH, translator. The work of the digestive glands, 2nd edn. Philadelphia: Chon $\mathrm{W}$, Griffin, 1910:48-59.

2 Knutson U, Olbe L. The gastric acid response to sham feeding in duodenal ulcer patients after proximal selective vagotomy. Scand $\mathcal{f}$ Gastroenterol 1973;8(suppl 20):16-17

3 Knutson U, Olbe L. Gastric acid response to sham feeding in the duodenal ulcer patient. Scand f Gastroenterol 1974;8:513-22.

4 Knutson U, Olbe L, Ganguli PC. Gastric acid and plasma gastrin responses to sham feeding in duodenal ulcer patients before and after resection of antrum and duodenal bulb. Scand $\mathcal{F}$ Gastroenterol 1974;9:351-6.

5 Richardson CT, Walsh JH, Cooper KA, et al. Studies on the role of cephalicvagal stimulation in the acid secretory response to eating in normal human subjects. $\mathcal{F}$ Clin Invest 1977;60:435-41.

6 Feldman M, Richardson CT. Role of thought, sight, smell, and taste of food in the cephalic phase of gastric acid secretion in humans. Gastroenterology 1986;90:428-33.

7 Feldman M, Richardson CT, Taylor IA, et al. Effect of atropine on vagal release of gastrin and pancreatic polypeptide. f Clin Invest 1979;63:294-8.

8 Schoon IM, Olbe L. Inhibitory effect of cimetidine on gastric acid secretion vagally activated by physiologic means in duodenal ulcer patients. Gut 1978;19:27-31

9 Feldman M, Dickerman RM, McClelland RN, et al. Effect of selective proximal vagotomy on food-stimulated gastric acid secretion and gastrin release in patients with duodenal ulcer. Gastroenterology 1979;76:926-31.

10 Feldman M, Richardson CT. 'Partial' sham feeding releases gastrin in normal human subjects. Scand $\mathcal{F}$ Gastroenterol 1981;16:13-16.
11 Erspamer V, Melchiorri P. Active polypeptides of the amphibian skin and their synthetic analogues. Pure Appl Chem 1973;35:463-94.

12 Erspamer V, Erspamer GF, Melchiorri P, et al. Occurrence and polymorphism of bombesin-like peptides in the gastrointestinal tract of birds and mammals. Gut 1979;20:1047-56.

13 Varner AA, Modlin IM, Walsh JH. High potency of bombesin for stimulation of human gastrin release and gastric acid secretion. Regul Pept 1981;1:289-96.

14 Hirschowitz BI, Tim LO, Helman CA, et al. Bombesin and G-17 dose responses in duodenal ulcer and controls. Dig Dis Sci 1985;30:1092-103.

15 El-Omar EM, Penman ID, Ardill JES, et al. Helicobacter pylori infection and abnormalities of acid secretion in patients with duodenal ulcer disease. Gastroenterology 1995;109:681-91.

16 El-Omar EM, Oien K, El-Nujumi A, et al. Helicobacter pylori infection and chronic gastric acid hyposecretion. Gastroenterology 1997;113:15-24.

17 McDonald TJ, Nilsson G, Vagne M, et al. A gastrin releasing peptide from the porcine non-antral gastric tissue. Gut 1978;19:767-74

18 McDonald TJ, Jornvall H, Nilsson G, et al. Characterization of a gastrin releasing peptide from porcine nonantral gastric tissue. Biochem Biophys Res Commun 1979;90:227-33.

19 Burnett N. Gastrin-releasing peptide. In: Walsh JH, Dockray GJ. Gut peptides: biochemistry and physiology. New York: Raven Press, 1994:423-45.

20 Hildebrand P, Lehmann FS, Ketterer S, et al. Regulation of gastric function by endogenous gastrin releasing peptide in humans: studies with a specific gastrin releasing peptide receptor antagonist. Gut 2001;48:23-8.

\section{Surviving too long in Crohn's disease}

Intestinal inflammation results from derangement of those mechanisms of innate and acquired immunity which subtly regulate the local immune response. ${ }^{1}$ This is the case in Crohn's disease and coeliac disease, both characterised by marked mucosal lymphocyte infiltration, abnormal $\mathrm{T}$ cell activation, and upregulation of Th 1 cytokines. $^{2}$

In recent years another piece has been added to the entangled puzzle of intestinal inflammation. Apoptosis, a highly controlled process of cell death, ${ }^{3}$ modulates immune and inflammatory responses by limiting expansion of activated $T$ lymphocytes and deleting autoreactive $T$ cell clones. ${ }^{45}$ At the intestinal mucosal level, this process may be of particular relevance ensuring that physiological lamina propria $T$ cell activation, due to chronic exposure to dietary antigens and exogenous pathogens, does not result in inflammatory tissue damage. Otherwise, defective $\mathrm{T}$ cell apoptosis may lead to a state of uncontrolled intestinal inflammation, and has been reported in coeliac disease ${ }^{6}$ and in Crohn's disease. ${ }^{78}$ In the former, decreased lymphocyte apoptosis has been found at the level of the epithelial compartment, ${ }^{6}$ and this defect, favouring expansion of intraepithelial lymphocytes with an abnormal phenotype and a restricted repertoire, may precede the onset of refractory sprue ${ }^{9}$ or $\mathrm{T}$ cell lymphoma. ${ }^{10}$ Unlike coeliac disease, in Crohn's disease the reduced susceptibility to undergo programmed cell death affects lamina propria $T$ cells, which have been shown to be resistant to CD2 mediated apoptosis, ${ }^{7}$ and is possibly due to an imbalance of the anti- and proapoptotic regulatory gene products Bcl-2 and Bax. $^{8}$

In this issue of $G u t,{ }^{11}$ Itoh et al describe Bcl-2 family protein levels, ratios, and correlations in peripheral and lamina propria $\mathrm{T}$ cells isolated from patients with inflammatory bowel diseases (see page 35). They expand their previous report $^{8}$ by studying purified mucosal $\mathrm{T}$ cells, including measurement of $\mathrm{Bcl}-\mathrm{x}_{\mathrm{L}}$, and correlating $\mathrm{Bcl}-2, \mathrm{Bcl}-\mathrm{x}_{\mathrm{L}}$, and Bax expression levels. Their results show that the low Bax level and consequent increase in the $\mathrm{Bcl}-\mathrm{x}_{\mathrm{L}} / \mathrm{Bax}$ ratio in lamina propria $\mathrm{T}$ cells may provide an explanation for the resistance of such cells to apoptosis in Crohn's disease.
Although the subject of this paper is not entirely novel, these findings suggest new molecular insights into some of the possible mechanisms underlying mucosal inflammation in Crohn's disease, comprehension of which may provide the basis for potentially new therapeutic strategies.

If intestinal inflammation is accompanied by excessive immune cell survival in Crohn's disease, agents that have the capacity to increase $\mathrm{T}$ cell apoptosis, as shown recently in experimental colitis for blockade of interleukin (IL)-12 12 or IL-6 trans signalling pathway, ${ }^{13}$ may be particularly effective as a form of therapy for this condition. IL-12, a key cytokine in determining the outcome of the effector $\mathrm{T}$ cell response, may account for the predominance of the Th1 response in Crohn's disease. ${ }^{14}$ Produced mainly by monocytes and macrophages in response to bacteria, bacterial products, or viruses, IL-12 promotes Th1 cell differentiation. It has been shown recently that antibodies to IL-12, which suppress experimental Th1 mediated colitis, seem to exert their therapeutic effects by induction of lamina propria $T$ cell apoptosis via a Fas dependent mechanism. ${ }^{12}$ In addition, as $\mathrm{T}$ cells could require IL-12 to maintain levels of key intracellular antiapoptotic proteins, anti-IL-12 may restore lymphocyte apoptosis by downregulating $\mathrm{Bcl}-2$ proteins (fig $1 \mathrm{~A}) .{ }^{12}$

Concerning the therapeutic effect of anti-IL-6 receptor, Atreya and colleagues ${ }^{13}$ identified a direct pathogenic role for the complex of IL-6 and its soluble receptor (sIL-6R) in Crohn's disease and showed the therapeutic potential of disrupting this form of cytokine signalling. They demonstrated that lamina propria macrophages release sIL-6R which may complex with IL-6 and stimulate gp130 on the surface of intestinal lamina propria $\mathrm{T}$ cells, leading to a STAT-3 dependent cascade of antiapoptotic genes such as Bcl-2 and Bcl- $x_{\mathrm{L}}$ and then to apoptosis resistance. By blocking the IL-6 trans signalling pathway, restoration of T cell susceptibility to apoptosis leads to suppression of Th1 mediated colitis in several animal models of chronic intestinal inflammation (fig 1B) ${ }^{13}$ Promoting lamina propria $\mathrm{T}$ cell apoptosis also seems to be the basis for the therapeutic benefit of antibodies to tumour necrosis factor $\alpha$ in active Crohn's disease ${ }^{15}$ but the mechanisms underlying this effect are at the present under investigation.

Recent studies on mucosal responses in $\mathrm{T}$ cell receptor (TCR) transgenic mice suggest novel strategies of 


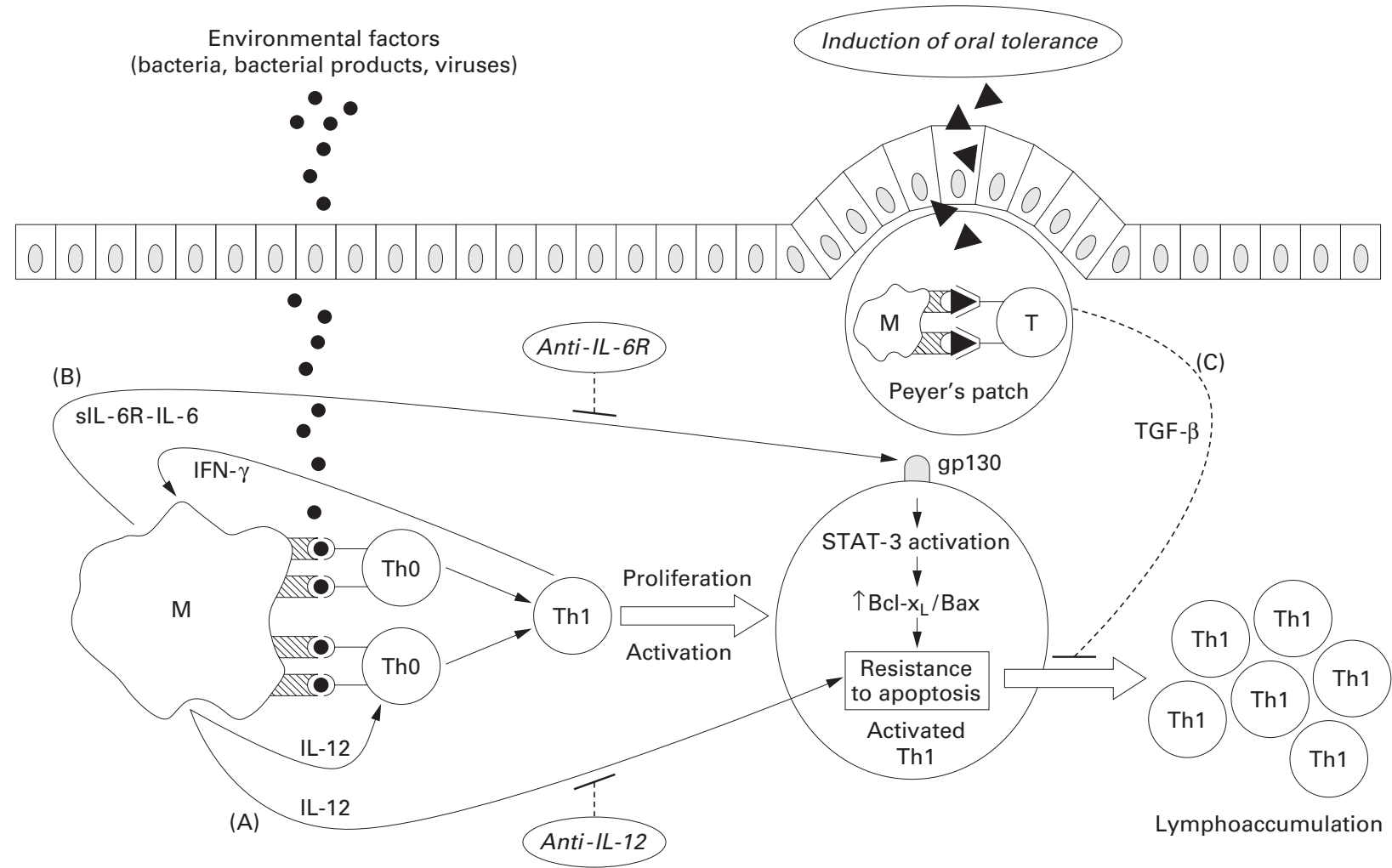

Figure 1 Potential strategies to hamper lymphoaccumulation by targeting defective T cell apoptosis in animal models of Crohn's disease. (A) Interleukin 12 (IL-12), produced by macrophages (M) in response to putative environmental factors, promotes differentiation of Th1 cells, which in turn upregulate macrophage IL-12 synthesis by releasing interferon $\gamma(I F N-\gamma)$. Antibodies to IL-12 exert their therapeutic properties by reinduction of T cell apoptosis. (B) Soluble receptor of interleukin 6 (sIL-6R), released by macrophages, may complex with IL-6 and stimulate gp130 on the T cell surface, leading to a STAT-3 dependent cascade of antiapoptotic genes (Bcl-2 and Bcl- $x_{L}$ ) and then to apoptosis resistance. Antibodies to IL-6R prevent this antiapoptotic pathway. (C) Tolerance induction following oral antigen administration may result in $T$ cell production of transforming growth factor $\beta$ (TGF- $\beta$ ) which mediates apoptotic deletion of T cells thus avoiding lymphoaccumulation.

downregulation of abnormal $\mathrm{T}$ cell survival by means of tolerance induction following oral antigen administration, and this may be a promising new approach for the treatment of Th1 $\mathrm{T}$ cell mediated experimental colitis and Crohn's disease. ${ }^{16}$ Oral administration of ovalbumin (OVA) to OVA-TCR transgenic mice results in induction of $\mathrm{T}$ cells producing transforming growth factor $\beta$ which mediate oral tolerance in a process that is at least partly characterised by apoptotic deletion of Th1 T cells, both in Peyer's patches and elsewhere (fig 1C). ${ }^{17}$

Taken together, these findings suggest that future strategies to defeat intestinal inflammation should include downregulation of excessive immune cell survival by targeting $\mathrm{T}$ cell apoptosis. However, further studies are needed to investigate the role of other cytokines involved in tissue injury, such as IL-15, which is highly expressed in Crohn's disease ${ }^{18}$ and seems to protect mucosal $\mathrm{T}$ cells from apoptosis. ${ }^{19}$ Only by defining the intricate connection of molecular mechanisms underlying defective $T$ cell death will we be able to solve the problem of $\mathrm{T}$ cells surviving too long in Crohn's disease.

\section{A DI SABATINO}

G R CORAZZA

Gastroenterology Unit, IRCCS Policlinico S Matteo,

University of Pavia, Pavia, Italy

Professor G R Corazza, Unità di Gastroenterologia dell'Università di Pavia, IRCCS Policlinico S Matteo, Piazzale Golgi 5, 27100 Pavia,

Italy.gr.corazza@smatteo.pv.it

1 Fiocchi C. Intestinal inflammation: a complex interplay of immune and nonimmune cell interactions. Am f Physiol 1997;273:G769-75.

2 nonimmune cell interactions. Am Pender SLF T cells orchestrate intestinal mucosal shape and integrity. Immunol Today 1999;20:505-10.

3 Thompson CB. Apoptosis in the pathogenesis and treatment of disease. Science 1995;267:1456-62.
4 Akbar AN, Salmon M. Cellular environments and apoptosis: tissue microenvironment control activated T-cell death. Immunol Today 1997;18: $72-6$

5 Van Parijs, Abbas AK. Homeostasis and self-tolerance in the immune system: turning lymphocytes off. Science 1998;280:243-8.

6 Di Sabatino A, Ciccocioppo R, D'Alò S, et al. Intraepithelial and lamina propria lymphocytes show distinct patterns of apoptosis, whereas both the populations are active in Fas-based cytotoxicity in coeliac disease. Gut 2001;49: (in press)

7 Boirivant M, Marini M, Di Felice G, et al. Lamina propria T cells in Crohn's disease and other gastrointestinal inflammation show defective CD2 disease and other gastrointestinal inflammation show defection
pathway-induced apoptosis. Gastroenterology 1999;116:557-65.

8 Ina K, Itoh J, Fukushima K, et al. Resistance of Crohn's disease T cells to multiple apoptotic signals is associated with a Bcl-2/Bax mucosal imbalance. F Immunol 1999;163:1081-90.

9 Cellier C, Delabesse E, Helmer C, et al. Refractory sprue, coeliac disease, and enteropathy-associated T-cell lymphoma. French Coeliac Disease Study Group. Lancet 2000;356:203-8.

10 Spencer J, Cerf-Bensussan N, Jarry A, et al. Enteropathy-associated T cell lymphoma is recognized by a monoclonal antibody (HML-1) that defines a membrane molecule on human mucosal lymphocytes. Am $f$ Pathol 1988;132:1-5.

11 Itoh J, de la Motte C, Strong SA, et al. Decreased Bax expression by mucosal T cells favors resistance to apoptosis in Crohn's disease. Gut 2001;49:3541.

12 Fuss IJ, Marth T, Neurath MF, et al. Anti-interleukin 12 treatment regulates apoptosis of Th1 T cells in experimental colitis in mice. Gastroenterology 1999;117:1078-88.

13 Atreya R, Mudter J, Finotto S, et al. Blockade of interleukin 6 trans signaling suppresses T-cell resistance against apoptosis in chronic intestinal inflammation: evidence in Crohn disease and experimental colitis in vivo. Nat Med 2000;6:583-8.

14 Pallone F, Monteleone G. Interleukin 12 and Th1 responses in inflammatory bowel disease. Gut 1998;43:735-6.

15 van Deventer SJH. Oral presentation. Symposium on trends in inflammatory bowel disease therapy 1999, Vancouver, Canada, 1999.

16 Marth T, Strober W, Seder RA, et al. Regulation of transforming growth factor- $\beta$ production by interleukin-12. Eur $\mathcal{F}$ Immunol 1997;27:1213-20.

17 Marth T, Strober W, Kelsall L. High dose oral tolerance in ovalbumin TCRtransgenic mice: systemic neutralization of IL-12 augments TGF- $\beta$ secretion and T cell apoptosis. F Immunol 1996;157:2348-57.

18 Liu Z, Geboes K, Colpaert S, et al. IL-15 is highly expressed in inflammatory bowel disease and regulates local $\mathrm{T}$ cell-dependent cytokine production. F Immunol 2000;164:3608-15.

19 Bulfone-Paus S, Ungureanu D, Pohl T, et al. Interleukin-15 protects from lethal apoptosis in vivo. Nat Med 1997;3:1124-9. 


\section{The subtleties of intestinal metaplasia}

Even if its incidence has decreased due to the influence of environmental and nutritional factors, gastric carcinoma remains a major concern because of its very poor prognosis. Screening for precancerous conditions, including intestinal metaplasia, is one method of improving the prognosis of gastric carcinoma. Nevertheless, the implications for the use of endoscopic surveillance in patients with intestinal metaplasia of the stomach are still unknown.

As suggested by Grötzinger et al in this issue of Gut, ${ }^{1}$ molecular changes (gain or loss of protein expression) are undoubtedly the first sign of metaplasia; the use of antibodies against specific proteins of the small intestine such as LI-cadherin or villin may help to diagnose metaplasia (see page 73 ). ${ }^{2}$ None the less, we cannot substitute the histological definition of intestinal metaplasia with molecular changes or "subtle metaplasia", as it is called by the authors, until the prognostic value, and particularly the relationship between protein expression and risk of cancer, have been assessed in greater detail.

Intestinal metaplasia of the stomach is characterised by morphological similarity to the enterocytes, Paneth cells, and goblet cells; it shows characteristics of absorbing mucosa, the presence of a striated border, and brush border structures. Histopathological and histochemical studies allow the identification of at least two types of intestinal metaplasia: (1) complete type, also designated type I, which is characterised by the presence of absorptive cells, Paneth cells, and goblet cells secreting sialomucins, and corresponds to the small intestine phenotype; and (2) incomplete type, including types II and III, which is characterised by the presence of columnar and goblets cells secreting sialomucins (type II) and sulphomucins (type III). ${ }^{3}$ It has been shown that type III intestinal metaplasia is associated with an increased risk of malignant transformation whereas the putative value of types I and II intestinal metaplasia remains controversial. ${ }^{4}$ Intestinal metaplasia of the stomach is frequent and we should continue to find markers that can distinguish between patients at low and high risk of developing carcinoma. The subcellular distribution of LI-cadherin or semiquantative estimation of immunoreactivity according to the type of metaplasia have to be studied: they may be helpful in discriminating between patients in terms of prognosis.

The currently accepted hypothesis is that gastric carcinogenesis involves a series of histological stages from normal gastric epithelium to intestinal-type gastric carcinoma, constituting sequential steps in the process of human gastric carcinogenesis. However, it is not clear whether intestinal metaplasia constitutes a precancerous lesion in itself or provides a milieu conducive to cancer growth in the surrounding mucosa. Grötzinger et al speculate on a role for LI-cadherin in the morphogenesis of tumour cells. Early induction of LI-cadherin in metaplasia and late loss of expression in undifferentiated adenocarcinoma may merely reflect differentiation rather than a role for LI-cadherin in the morphogenesis of tumour cells. On the other hand, the different patterns of LI-cadherin localisation in the various types of neoplasia may suggest a role in morphogenesis.

R ROUZIER S ROBINE

Institut Curie-Research Division,

Paris, France

Correspondence to: Dr S Robine, Institut Curie-Research Division, UMR 144 CNRS Laboratory, Morphogenesis et Cellular Signalisation, 26 Rue D’Ulm,

Fr-75231, Paris Cedex 05, France. sylvie.robine@curie.fr

1 Grötzinger C, Kneifel J, Patschan D, et al. LI-cadherin: a marker of gastric metaplasia and neoplasia. Gut 2001;49:73-81.

2 Osborn M, Mazzoleni G, Santini D, et al. Villin, intestinal brush border hydrolases and keratin polypeptides in intestinal metaplasia and gastric cancer; an immunohistologic study emphasizing the different degrees of intestinal and gastric differentiation in signet ring cell carcinomas. Virchows intestinal and gastric differentiation in signe

3 Filipe MI. Borderline lesions of the gastric epithelium: new indicators of gastric risk and clinical implications. In: Fenoglio-Preiser CM, Wolff $M$, Rilke F, eds. Progress in surgical pathology. USA: Field and Wood, 1992:269-90.

4 Rokkas T, Filipe MI, Sladen GE. Detection of an increased incidence of early gastric cancer in patients with intestinal metaplasia type III who are closely followed up. Gut 1991;32:1110-3. 